\title{
Detecting, mapping and classifying wetland fragments at a landscape scale
}

\author{
Alanna J. Rebelo ${ }^{\mathrm{a}, \mathrm{b}, *}$, Paul Scheunders ${ }^{\mathrm{c}}$, Karen J. Esler ${ }^{\mathrm{b}, \mathrm{d}}$, Patrick Meire ${ }^{\mathrm{a}}$ \\ ${ }^{a}$ Ecosystem Management Research Group (ECOBE), Department of Biology, University of Antwerp, Universiteitsplein 1C, Wilrijk 2610, Belgium \\ b Department of Conservation Ecology and Entomology, Stellenbosch University, JS Marais Building, Victoria Street, 7600, Private Bag $\times 01$, Matieland, 7602, \\ Stellenbosch, South Africa \\ ${ }^{c}$ Vision Lab, Department of Physics, University of Antwerp, Universiteitsplein 1C, Wilrijk 2610, Belgium \\ d Centre for Invasion Biology (C.I.B), Stellenbosch, South Africa
}

\section{A R T I C L E I N F O}

\section{Keywords:}

Palmiet wetlands

Conservation planning

Ecosystem service assessments

Habitat suitability modelling

Wetland inventories

Historical analysis

\begin{abstract}
A B S T R A C T
Small valley-bottom wetlands $\left(<5 \mathrm{~km}^{2}\right)$ are often overlooked in conservation and restoration efforts due to the difficulty to discriminate them in large regions. However due to their position in the landscape they are both critical for ecosystem service provision as well as highly threatened. Therefore there is a need to detect and map the extent of small valley-bottom wetlands to aid conservation and restoration efforts. We investigated five research questions concerning small, valley-bottom palmiet wetlands in the Cape Floristic Region (CFR), South Africa: (1) What is the best technique to detect palmiet wetlands?, (2) what is the best approach to map their extent?, (3) how best to analyse their potential extent and historical changes?, (4) what is their current extent and distribution and how has this changed historically?, and (5) what are the main drivers of this change? We used three different approaches to answer the various questions: multispectral imagery (the Landsat series) combined with Support Vector Machine classification, aerial photograph analysis with photographs from three time-steps and predictive modelling of wetland habitat suitability (using the MaxEnt model). Our main findings suggest that (1) multispectral classification using Landsat8 was best for palmiet wetland detection (76\% accuracy), whereas (2) aerial photographs were the most useful in mapping extent. (3) Analysing changes in extent over time was best achieved using aerial photography, due to their high resolution and long historical record in South Africa (1940 compared to 1970 in the Landsat series). (4) South African palmiet wetlands are in decline, having decreased by on average $31 \%$ in area since the $1940 / 50$ s (overall loss of $6.36 \mathrm{~km}^{2}$ ). Palmiet wetlands have also become increasingly fragmented, with weighted wetland perimeter increasing by $29 \%$ over the same period. (5) The major driver of this appears to be gully erosion triggered by land-use change. The wider implication of these findings is that it is possible to detect small wetlands using freely available Landsat 8 data which could be useful to support local or regional conservation and restoration initiatives.
\end{abstract}

\section{Introduction}

Globally, wetlands are acknowledged to be valuable ecological infrastructure as they provide many essential ecosystem services to humans (Mitsch and Gossilink, 2000; Russi et al., 2013; Simonit and Perrings, 2011). Due to this value, many wetlands have been exploited or unsustainably used, resulting in estimated declines in global wetland extent of between $64-71 \%$ in the 20th century alone (Gardner et al., 2015). Countries that have ratified the Ramsar Convention (Ramsar, 1971) are obliged to implement planning to promote the wise use of wetlands and to develop policies for management and conservation (Gardner et al., 2015). Despite 169 countries signing this agreement, there are still negative trends; wetlands are continuing to be lost or degraded, and populations of wetland species are declining (Gardner et al., 2015). Additionally, the Convention on Biological Diversity (CBD, 1992) obliges contracting parties to rehabilitate and restore degraded ecosystems and manage biological resources which are important for the conservation of biological diversity (Glowka et al., 1994). To effectively manage and conserve wetlands, nations require up-to-date, accurate inventories of wetland occurrence and distribution and means of monitoring this (Li and Chen, 2005; Rebelo et al., 2009).

Satellite remote sensing is a useful tool for wetland detection, both in terms of distribution and extent. Certain wetland types (open inundated areas, bogs or fens) are frequently mapped using areas of inundation, focussing on the near infra-red part of the spectrum (Gala and Melesse, 2012; Knight et al., 2009), or a combination of this and chlorophyll indices, such as the normalised difference vegetation index (NDVI) (Landmann et al., 2010). Other types of wetlands (permanent

\footnotetext{
* Corresponding author at: Ecosystem Management Research Group (ECOBE), Department of Biology, University of Antwerp, Universiteitsplein 1C, Wilrijk 2610, Belgium.

E-mail address: AlannaJane.Rebelo@uantwerpen.be (A.J. Rebelo).
} 


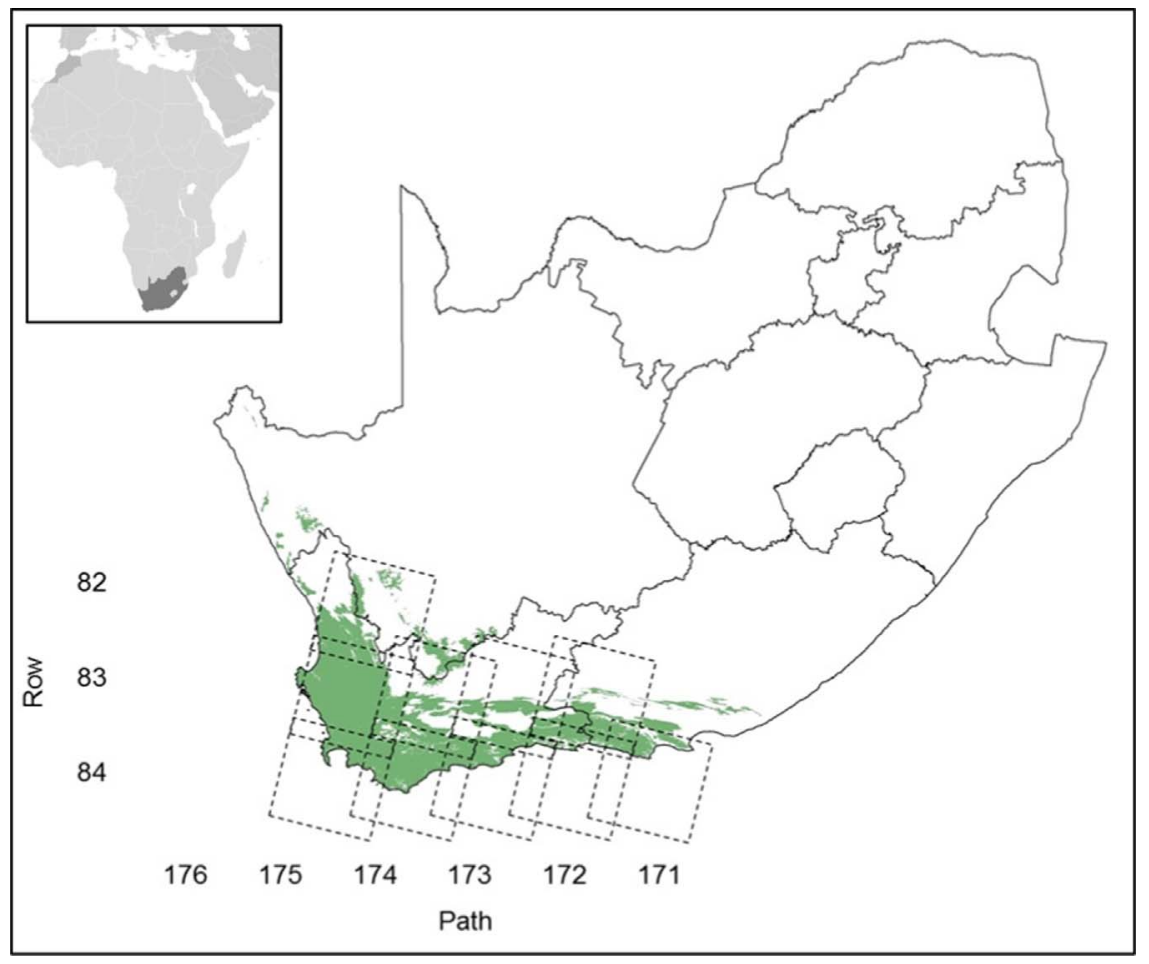

Fig. 1. The location of the Cape Floristic Region (green) within South Africa (inset) and the coverage of the 10 Landsat8 scenes selected for this study.

wetlands, marshes, swamps), where soil inundation is obscured by dense wetland vegetation, are mapped using vegetation spectral signatures (Kameyama et al., 2001; Thomas et al., 2015). No single sensor is ideal, and there are always trade-offs to consider (temporal frequency, spectral resolution, spatial resolution, cost). Digitization of aerial photography is perhaps the most accurate method of mapping wetland extent for small wetlands (Harvey and Hill, 2001); however the trade-off is that this needs to be a targeted approach, targeting a specific wetland once it has been located, and therefore is not a useful technique for wetland detection. In addition to using imagery, predictive models and Bayesian Networks have also been successful in mapping and detecting wetlands at local to regional scales. The MaxEnt species distribution model, based on the principal of maximum entropy, has been used to predict the occurrence of wetland communities with reasonable success (Hunter et al., 2012). Wetland occurrence is determined by complex interactions between geographic variables, such as altitude, gradient, and geology which influence groundwater, soils and climatic variables.

South Africa has ratified the Ramsar and Biological Diversity conventions, however wetlands continue to be degraded with over $65 \%$ threatened and half estimated to be destroyed (Nel and Driver, 2012). One of the nation's greatest challenges in wetland conservation is the lack of a comprehensive overview of the extent, diversity, distribution, status and relative importance of its wetlands (Rountree et al., 2009). The South African National Wetland Inventory (NWI), a national wetland classification system has been developed at a national scale and contains a set of 791 wetland ecosystem types (Driver et al., 2012). More recently, the National Freshwater Ecosystem Priority Areas (NFEPA) project was developed using GIS applications (Nel et al., 2011). However due to the large size of South Africa, 1.2 million $\mathrm{km}^{2}$, both of these national-scale inventories are coarse, and result in many important and threatened wetland systems being overlooked (van Deventer et al., 2016). If restoration strategies in South Africa, such as the current 'Working for Wetlands programme" (van Wilgen et al., 2012), are to succeed in prioritizing wetlands for restoration and conservation, it is essential to have a finer scale inventory of wetlands. Wetland occurrence in South Africa has been determined at finer scales, both for certain provinces (using modelling techniques such as Bayesian belief networks (Hiestermann and Rivers-Moore, 2015)) and for individual cities (e.g. City of Cape Town; Holmes and Pugnalin, 2016), but there are still important gaps.

We used three techniques to investigate the following five research questions concerning South African palmiet wetlands: (1) What is the best technique to detect palmiet wetlands?, (2) what is the best approach to map their extent?, (3) how best to analyse their potential extent and historical changes?, (4) what is their current extent and distribution and how has this changed historically?, and (5) what are the main drivers of this change? Palmiet wetlands are a unique, typically small $\left(<5 \mathrm{~km}^{2}\right)$ unchannelled valley-bottom wetland system occurring throughout the Cape Floristic Region (CFR) of South Africa. They get their name from the endemic wetland plant and ecosystem engineer: palmiet (Prionium serratum). Palmiet wetlands are thought to provide multiple ecosystem services to society, including flood attenuation (Rebelo et al., 2015), water purification and carbon sequestration (Rebelo, 2017). They are typically underlain by peatbeds between 0.5 and $10 \mathrm{~m}$ deep (Job, 2014; Nsor, 2007), and this is the ecological infrastructure that stores carbon, provides habitat for microbes which are thought to play a role in purifying water, and in combination with palmiet vegetation, dissipates the force of floodwaters (Rebelo, 2017). Despite the inherent value of these wetlands and their threatened status, there is no comprehensive understanding of where they remain, where they have been destroyed and what the main drivers of change are. The results of the comparison of techniques may be useful for other research at local or regional scales. The findings specific to palmiet wetlands would support the setting of restoration and conservation priorities within the Cape Floristic biodiversity hotspot.

\section{Methods}

\subsection{Study region \& wetlands}

The CFR of South Africa is one of 35 global biodiversity hotspots (Mittermeier et al., 2011; Myers et al., 2000) and covers 87,892 $\mathrm{km}^{2}$ at the south-western tip of southern Africa (Cowling and Heijnis, 2001) (Fig. 1). It is characterized by exceptionally high botanical diversity and 
endemism which is under threat (Myers et al., 2000; van Wyk and Smith, 2001). The CFR has a mediterranean-type climate in the west with varying degrees of summer drought and winter rainfall resulting from the passage of cold fronts (Midgley et al., 2003). Further towards the east there is more of a bimodal rainfall pattern. One of the greatest threats to the biodiversity of the CFR is the rapid expansion of towns and cities as well as the accompanying habitat transformation associated with agriculture, plantations and alien plant invasions (Cowling et al., 2003; Rebelo et al., 2011; Rebelo and Siegfried, 1992).

We used the three techniques: (i) multispectral remote sensing techniques, (ii) maximum entropy distribution modelling and (iii) aerial photograph analysis to answer the five research questions. We first used Landsat imagery to determine whether multispectral remotesensing was a suitable technique to map small wetlands (both in terms of detection, and accurately mapping extent) (research question $1 \& 2$ ) currently (Landsat8) and historically (Landsat1-3, 5). We used the output from the Landsat8 classification to select palmiet wetland fragments to use in aerial photograph analysis to compare the accuracy and effectiveness of this technique to the Landsat time-series analysis (research question 3). It was apparent from the earliest aerial photographs that some of the degradation had taken place prior to the first available imagery. Therefore to understand what the original extent of palmiet wetlands might have looked like, we attempted to model 'potential habitat distribution' using MaxEnt species distribution modelling.

\subsubsection{Technique 1: multispectral remote sensing}

2.1.1.1. Image acquisition and classification. Palmiet wetlands are sparsely distributed over the CFR, often forming long narrow bands in the bottom of valleys, varying from $30-550 \mathrm{~m}$ in width, and typically from a few hundred to a thousand metres in length. Therefore we selected the Landsat series due to their large swath width and historical archives. Ten Landsat8 images (level $1 \mathrm{~T}$ terrain corrected) covering the study area were downloaded from the Earth Explorer website from 2014 (Fig. 1). We tried to select images from spring to early summer (August-December 2014), as after the rainy winter season, the wetlands would be at their highest water levels and be easier to detect in the landscape (Ozesmi and Bauer, 2002). However in some cases this was not possible, due to extensive cloud cover. Therefore the scenes ranged in date from February to October. Images were converted from digital numbers to reflectance (except for the thermal bands which are preserved as temperature) in Grass7 using the i.toar-routine, and the Fmasks procedure was applied separately for cloud detection.

Regions of interest (ROI) were collected from each of these ten scenes to represent the main land-use/land-cover (LULC) classes throughout the images and, most importantly, for pure pixels containing palmiet wetlands. ROI were selected visually using the ROI tool in ENVI, either in true colour mode (bands 2, 3, 4: blue, green, red), or false colour (bands 4, 6, 7: red, SWIR1, SWIR2), or both. LULC classes included agriculture (irrigated and dryland), towns/cities, sand, rock, water, cloud, mountain fynbos vegetation, karoo vegetation, plantations, riparian alien tree invasions, and native forest. All non-palmiet ROI's were grouped together prior to classification. The classification was performed by the Support Vector Machine (SVM) algorithm, which has demonstrated its use in the analysis of remotely sensed images (Asadzadeh and de Souza Filho, 2016). However, as the palmiet wetland class is very small, a presence-only variant was selected to identify its occurrence. More specifically, the one-class extension by Schölkopf et al. (2000) was used in the implementation of LibSVM (Chang and Lin, 2011). We used the same techniques to map the recent historical palmiet wetland occurrence at two points in time: 1970s and 1980s using Landsat1-3 and Landsat5 respectively (Table 1). We transferred ROI's from the 2014 scenes onto those from the 1970s and 1980s and edited these ROI's to tailor them to the LULC of the time, using the satellite images as a reference.

\subsubsection{Classification validation and ground-truthing. For each}

classification, $80 \%$ of the ground reference points (pixels of the ROI's for palmiet wetlands) were set aside for training data. Of this $80 \%, 50 \%$ were used for training and $50 \%$ for validation. In the validation step, the available non-palmiet ROI's were included for parameter estimation, in order to reduce over-classification. The remaining independent $20 \%$ were used to test the accuracy of the classifications. F1-scores were calculated from the test set and are given as a score from 0 to 1 depending on the accuracy of the classification (\% true positives). An additional accuracy score (\%) was calculated for non-palmiet classification (\% true negatives). The final result of the Landsat8 classifications was also ground-truthed using two independent techniques. The first was using visual analysis through Google Earth Pro, which had a high enough resolution to allow the assessment of the wetland classification results. Random GPS coordinates were generated (321 in total) and each point on the classification was compared to Google Earth imagery. The second method used independent data on palmiet presence collected through the citizen science platform: iSPOT (https://www.ispotnature.org/communities/southern-africa). In total palmiet vegetation was recorded 55 times throughout the study region by citizen scientists. These 55 locations were checked on the imagery to determine whether the classifications had correctly classified palmiet, and an accuracy score (\%) was calculated. The classifications from the 1980s and 1970s were not possible to groundtruth, given that no data on wetland occurrence were found for these time periods.

\subsubsection{Technique 2: habitat suitability modelling}

The purpose of using habitat suitability modelling was to construct a probability map of the possible original occurrence and extent of palmiet wetlands within the CFR, before colonialists arrived in South Africa in the 17th century, dramatically changing LULC in South Africa (e.g. see Skead (2009)). We did this by only including input relating to its natural distribution (e.g. geology, soil, climate) and excluding input that would explain its decline (e.g. LULC, pollution). Modelling a wetland community, rather than species, using MaxEnt, has been shown to be possible (Hunter et al., 2012). Therefore we used the MaxEnt species distribution model, which is based on the ecological niche concept (Phillips et al., 2006). MaxEnt is a general-purpose machine learning method based on the principal of maximum entropy (Phillips et al., 2006). MaxEnt produces a results map showing the probability of species occurrence, ranging from 0 to 1 .

2.1.2.1. Input data and settings. Relevant model input variables were selected and data obtained from various organizations such as national government and research institutions (Appendix A). The output of the most recent (2010) aerial photograph analysis (raster file; technique 3) was converted to points (shapefile) in ArcMap and used as the input for wetland presence in the MaxEnt model. Sampling bias was controlled by inputting information on survey effort across the study region into the model (Merow et al., 2013). Since no palmiet wetland absence data exist, we used the non-palmiet regions of interest input from the multispectral remote sensing analysis. We used random seeding and set the number of replicates, from which the results could be averaged, to 15 . In addition we chose to withhold $25 \%$ of the data for testing the performance of the model, using a sub-sampling approach. We set the number of iterations to 5000, allowing the model enough time to converge. All other MaxEnt settings were left at their default values. The spatial resolution of the analysis is determined by that of the coarsest data set $(1.6 \times 1.6 \mathrm{~km})$, although all rasters were resampled to $46 \times 46 \mathrm{~m}$.

2.1.2.2. Model validation and assessment. MaxEnt has a number of inbuilt cross-validation options where the presence locations are divided into training and validation datasets (used for $\mathrm{K}$-fold cross validation). Goodness-of-fit statistics, or area under the receiveroperating characteristic curve (AUC), is the most popular model 
Table 1

Specifications of the products used in this study for various time steps.

\begin{tabular}{|c|c|c|c|c|c|}
\hline Product & Decade & Number of bands & Resolution & Swath Width/Area & Scale \\
\hline Landsat8 & 2010 & 11 & $30 \times 30 \mathrm{~m}$ & $185 \mathrm{~km}$ & - \\
\hline Landsat5 & 1980 & 4 & $60 \times 60 \mathrm{~m}$ & $185 \mathrm{~km}$ & - \\
\hline Landsat1-3 & 1970 & 4 & $60 \times 60 \mathrm{~m}$ & $185 \mathrm{~km}$ & - \\
\hline \multirow[t]{3}{*}{ Aerial photographs } & 2010 & - & $0.5 \mathrm{~m}$ & $6 \times 5 \mathrm{~km}$ & - \\
\hline & 1980 & - & $2.6-4.7 \mathrm{~m}$ (mean $3.6 \mathrm{~m})$ & $7.5 \times 7.5 \mathrm{~km}$ or $12.5 \times 12.5 \mathrm{~km}$ & $1: 30000-1: 50000$ \\
\hline & $1940 / 50$ & - & $1.9-2.9 \mathrm{~m}$ (mean $2.5 \mathrm{~m})$ & $5 \times 5 \mathrm{~km}$ or $7 \times 7 \mathrm{~km}$ & $1: 18000-1: 30000$ \\
\hline
\end{tabular}

Table 2

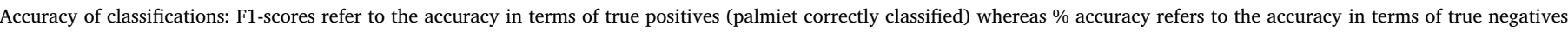
(non-palmiet correctly classified). The numbers in bold are the names of the images.

\begin{tabular}{|c|c|c|c|c|c|c|c|c|c|c|c|}
\hline \multirow[b]{2}{*}{$\#$} & \multirow[b]{2}{*}{ Path } & \multirow[b]{2}{*}{ Row } & \multicolumn{3}{|c|}{ Landsat8 2014} & \multicolumn{3}{|c|}{ Landsat5 1983-1987 } & \multicolumn{3}{|c|}{ Landsat1-3 1972-1978 } \\
\hline & & & & F1-Score & Accuracy (\%) & & F1-Score & Accuracy (\%) & & F1-Score & Accuracy (\%) \\
\hline 1 & 175 & 84 & 115 & 0.60 & 53.00 & 131 & 0.42 & 77.02 & 335 & 0.57 & 46.38 \\
\hline 2 & 175 & 83 & 291 & 0.82 & 75.32 & 131 & 0.64 & 58.82 & 313 & 0.67 & 64.71 \\
\hline 3 & 175 & 82 & 291 & 0.83 & 60.38 & 289 & 0.60 & 50.00 & 260 & 0.32 & 50.00 \\
\hline 4 & 174 & 84 & 236 & 0.71 & 63.24 & 218 & 0.40 & 68.75 & 298 & 0.40 & 43.90 \\
\hline 5 & 174 & 83 & 268 & 0.54 & 52.00 & 330 & 0.64 & 54.55 & 312 & 0.73 & 66.67 \\
\hline 6 & 173 & 84 & 245 & 0.74 & 73.23 & 115 & 0.85 & 79.57 & 347 & 0.64 & 54.05 \\
\hline 7 & 173 & 83 & 277 & 0.75 & 42.31 & 115 & 0.30 & 69.56 & 347 & 0.73 & 65.22 \\
\hline 8 & 172 & 84 & 174 & 0.86 & 75.00 & 204 & 0.31 & 61.76 & 070 & 0.53 & 63.33 \\
\hline 9 & 172 & 83 & 174 & 0.88 & 76.67 & 321 & 0.66 & 55.26 & 274 & 0.71 & 58.97 \\
\hline \multirow[t]{2}{*}{10} & 171 & 84 & 279 & 0.84 & 76.19 & 314 & 0.73 & 58.70 & 15 & 0.33 & 65.00 \\
\hline & & & mean & 0.76 & 64.73 & & 0.56 & 63.40 & & 0.56 & 57.82 \\
\hline
\end{tabular}

evaluation for MaxEnt (Merow et al., 2013). Alternatively, binary presence-absence predications can be generated from the model output using thresholds and this can be ground-truthed using independent data sets. We used AUC and the 10th percentile training presence logistic threshold to define the minimum probability of suitable habitat. Since no data exist on the historical extent of palmiet wetlands, the distribution cannot be ground-truthed. However the output was visually compared with current wetland extent to assess whether the modelled results are feasible.

\subsubsection{Technique 3: aerial photograph analysis}

2.1.3.1. Image acquisition and digitization. Palmiet wetland fragments were identified for further analysis using the results of the Landsat8 classification combined with expert knowledge. True palmiet wetlands were identifiable as relatively larger areas of dense pixels, whereas palmiet wetlands falsely identified by the algorithm tended to be made up of single pixels, sparsely spread. Eight wetland fragments were selected for further analysis. Aerial photographs from three time slices: 1940/50s, 1980s and 2010s were acquired from the Chief Directorate of National Geo-spatial Information (Cape Town, South Africa) for these eight sites. Wetland fragments range from about $2.75-13 \mathrm{~km}$ in size (wetland length). Aerial photographs were selected from three time steps (Table 1). The aerial photographs from 2010 were already rectified and georeferenced. These photographs were used to rectify and georeference the historical photographs in ArcMap. Wetland vegetation in each of the aerial photographs was digitized, making effort to consider the same wetland fragment in all three time slices for each site. Alien trees, erosion and agriculture in the valley-bottoms were excluded, but besides this no effort was made to distinguish healthy (pristine) wetland vegetation from degraded vegetation, nor to distinguish wetland vegetation types; as this would not have been possible to discriminate in the historical imagery. Wetland area and perimeter were calculated in ArcMap using the 'calculate geometry' tool, and the relative perimeter was calculated (perimeter/area).

\subsection{Analysis \& statistics}

All resulting maps of historical and current palmiet wetland occurrence were collated in ArcMap and screened for reliability and accuracy. We chose the most reliable of the three approaches to analyse changes in wetland area and distribution over time. The statistical difference in change of wetland area and perimeter was tested using linear mixed models in $\mathrm{R}$ and an $F$-test with Kenward-Roger correction, after testing for normality. To establish which years differed from each other, a Tukey post hoc test was used. Where wetlands were predicted to be present historically, but are no longer present, the LULC replacing them were obtained from Google Earth Pro and recorded. These findings were analyzed to determine the main drivers of palmiet wetland decline within the CFR. The frequency with which these drivers affected each wetland was recorded, and from this a percentage was calculated to indicate the relative importance of each driver.

\section{Results}

\subsection{Technique 1: landsat classification results}

Landsat8 classification produced reasonable results for the current occurrence of palmiet wetlands within the CFR of South Africa (Fig. 2, Table 2). There was some slight over-classification, especially at higher altitudes, where there are no palmiet wetlands present (Fig. 2). There was also some over-classification within wetlands themselves as the algorithm sometimes struggled to discriminate between palmiet wetland vegetation, and other wetland vegetation types/alien vegetation. From the ground-truthed results using iSPOT records, a score of $63 \%$ for true positives was obtained, whereas from the 321 randomly generated points checked in Google Earth, the accuracy score was $100 \%$ for true negatives. Using Landsat8 imagery to detect and map small wetland fragments seems to be a feasible technique.

Overall for the historical imagery, Landsat5 and Landsat1-3 classification results were not as promising (Table 2, Fig. 2). The coarser spatial $(60 \times 60 \mathrm{~m})$ and spectral (4 bands) resolutions made the classification of small wetland fragments challenging. Palmiet wetlands were 


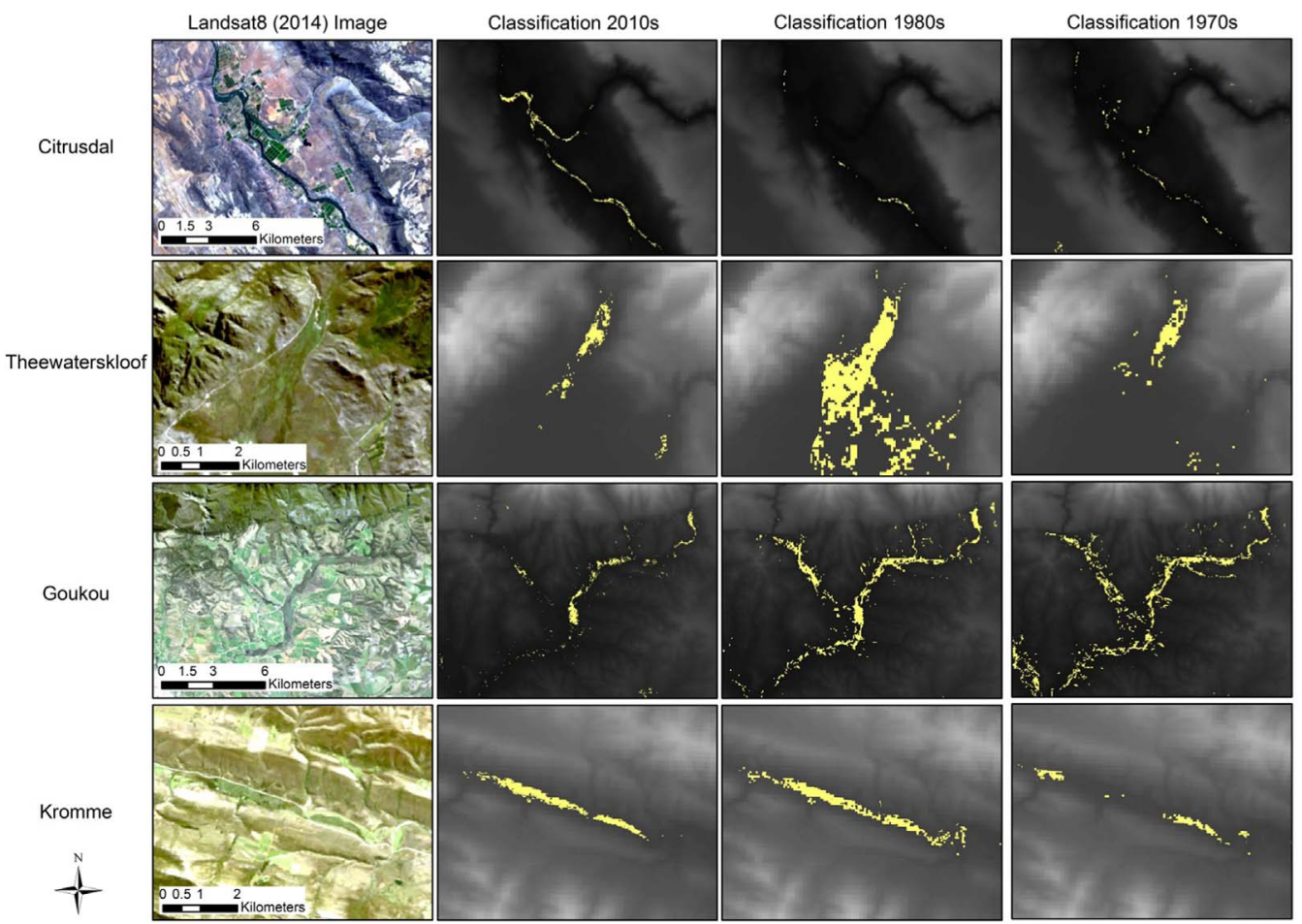

Fig. 2. Results of the Landsat classifications for the 1970s, 1980s and 2010s from Landsat1-3, Landsat5 and Landsat8 respectively for four palmiet wetland sites in the Cape Floristic Region (CFR) of South Africa. For the location of these sites within the CFR, see Fig. 5. still detectable; however there was significant over-classification, especially for Landsat5 imagery (Fig. 2). Therefore the results of classifications from the 1980s and 1970s were not used in further analyses to detect change in wetland extent over time. Landsat historical imagery appears to have limitations for accurately mapping the extent of small wetland fragments.

\subsubsection{Spectral signatures}

Spectral signatures can be useful in untangling the causes of overclassification of satellite remote sensing imagery. In the case of Landsat8 imagery, certain classes were more difficult to discriminate than others (i.e. had similar spectral signatures). Spectral signatures for palmiet were most similar to irrigated agriculture, plantations/alien invasion, Afromontane Forest, Albany Thicket and some Fynbos types (Fig. 3, Fig. 4). From the average spectra collected and displayed in Fig. 4, it seems that the spectral signature for palmiet wetlands is most similar to stands of dense trees, either alien (plantations/invasions) or indigenous (Afromontane Forest, Albany Thicket) or irrigated agriculture. This may be due to the high vegetation biomass or high wateruse of these LULC types, or a combination of both, rendering them similar to palmiet wetland spectra.

\subsection{Technique 2: habitat suitability modelling}

Overall the MaxEnt model successfully identified some fragments of existing palmiet wetland patches as 'suitable' habitat (Fig. 5). It had an area under the receiver-operating characteristic curve of $0.81(0.5$ is considered no better than random, 1 is considered good model performance). However it was not able to extrapolate this information to where these wetlands may once have occurred (e.g. where they are known to have been replaced by an impoundment or agriculture). Overall this model -with the currently available spatial layers (input data) - does not successfully predict the historical extent of small valleybottom wetland patches.

Ten variables were the most important in predicting palmiet wetland habitat suitability, accounting for $90 \%$ of the predictive contribution (Table 3). However not all of these variables and thresholds are the most sensible. For example, the threshold that the model set for

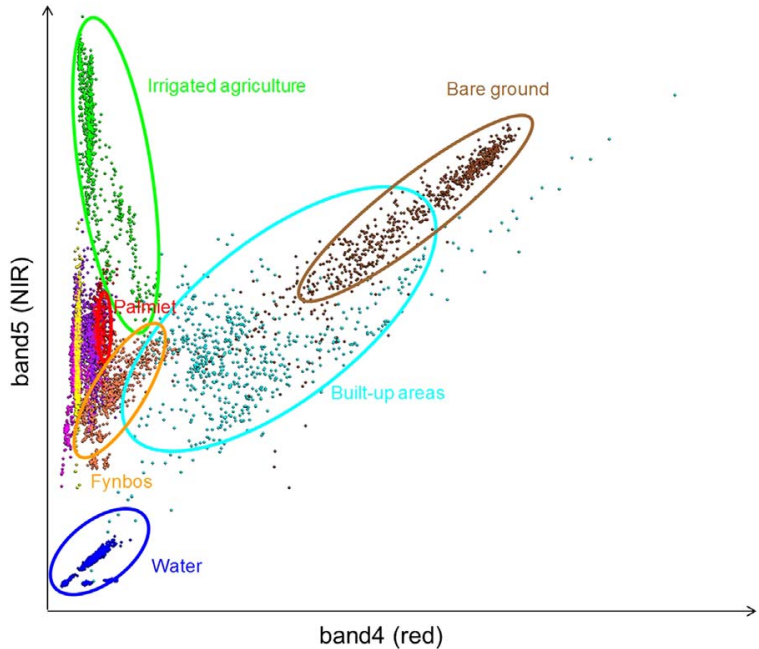

Fig. 3. Spectral signatures of the major land-use/land-cover classes within the Cape Floristic Region, South Africa extracted from regions of interest taken from 2014 Landsat8 imagery. Two bands are plotted against each other: band4 (red) and band5 (NIR). The easily distinguishable classes are indicated on the figure, but all classes are listed here: palmiet wetlands, irrigated agriculture, plantations/alien invasion, Afromontane Forest, — bare ground, w water, built up areas, Fynbos, albany Thicket.

slopes that are suitable for palmiet wetlands was too high. The model set the threshold at between $5^{\circ}$ and $18^{\circ}$ where we have found palmiet wetlands not to occur above slopes of about $5^{\circ}$. This accounts for some of the over-classification observed in Fig. 5. Secondly, one of the important variables is found to be 'precipitation of the driest quarter', which clearly separates the western and eastern parts of the CFR, being low in the west (9-80 $\mathrm{mm}$ ) and high in the east (80-241 mm), resulting in a spatial bias due to the two different climatic regions. However palmiet wetlands occur in both regions, and therefore it is strange that this was selected by the model to be important in predicting palmiet wetland occurrence. 


\subsection{Technique 3: aerial photograph analysis}

Eight remaining palmiet wetland fragments were identified in the CFR from the Landsat8 classification results, and these were used in aerial photograph analysis. This technique was found to be the most accurate in examining historical changes in wetlands, yielding results which were comparable from one time period to the next, unlike the historical Landsat analysis. Wetland change is shown visually for four wetland fragments in Fig. 6 (details in Table 4). In contrast the MaxEnt modelling output is shown, giving an impression of the coarseness of the results. Also shown is the classification of these wetland fragments according to the South African National Freshwater Ecosystem Priority Areas (NFEPA) project (Nel et al., 2011). In each case these wetlands are miss-classified in NFEPA, either as 'channelled' valley-bottom wetlands, or as floodplain wetlands. These wetlands are all unchannelled valley-bottom wetlands, with the exception of the Citrusdal wetland. This Citrusdal wetland has likely artificially been channelized before the 1940s when extensive systems of canals were dug parallel to the wetland system, and a municipal dam was built. The NFEPA classifications also do not recognise wetland degradation, or where the wetland no longer exists due to agriculture (Fig. 6).

\subsection{Wetland change analysis}

Palmiet wetland extent within the CFR has significantly declined over the past $60-70$ years $(\mathrm{F}=5.21$, $\mathrm{df}=14, \mathrm{p}<0.05)$. Overall decline in area is $31 \%$; at some sites wetland area does not change at all and in other sites it declines by over half over the last $60-70$ years (55\%) (Table 4). Most of these significant changes took place between the 1940/50s and the 1980s ( $\mathrm{t}=2.4, \mathrm{df}=7, \mathrm{p}<0.05$ ), though it is clear from the earliest photographs that major changes to these systems had already been made before the first aerial photographs were available (1940s). Wetland weighted perimeter (relative to the area of the wetland) increased significantly by $29 \%$ over the last $60-70$ years ( $\mathrm{F}=$ 5.20 , df $=14, \mathrm{p}<0.05$ ), indicating that remaining palmiet wetlands are becoming increasingly fragmented (Appendix A, Table A2). Every palmiet wetland experienced increased fragmentation, ranging from $5 \%$ to $39 \%$.

The major drivers of wetland change in South Africa can be divided into two categories: those indirectly affecting wetland extent by altering hydraulics and those directly affecting wetland extent by replacing wetland surface area (Rebelo et al., 2015). Bisecting roads are one of the most common drivers negatively impacting palmiet wetlands, affecting each of the eight wetland fragments investigated (Table 5). Roads cause knick-points in these wetland systems, often resulting in erosion, which eventually drains the wetland (Job, 2014), see Plate A1. Once this erosion begins, it is impossible for the system to recover without active rehabilitation, which is costly. This wetland drainage results in a shift in vegetation communities, often encouraging the recruitment of alien vegetation. Other drivers impacting wetland hydraulics include water canals which drain palmiet wetlands, and dams: either small farm dams, or large municipal ones. Examples of the second type of driver include irrigated agriculture and alien plant invasion. Sections of palmiet wetlands have been replaced by agriculture, and others have become invaded by non-native plants, either trees (e.g. Acacia mearnsii, Eucalypt sp., Pinus sp. or Quercus sp.), or weedy plants such as Rubus sp.

\section{Discussion}

\subsection{Comparison of techniques to map small wetlands}

We found Landsat8 imagery combined with SVM classification to be highly effective at detecting palmiet wetlands in a large region. This result was refined using aerial photograph analysis, by selecting eight of the largest remaining palmiet wetland fragments, and performing digitization at high resolution to accurately map current wetland extent. Historical wetland mapping using multispectral remote sensing was more challenging. The results from the SVM classification of historical Landsat imagery were unreliable, a result of differing rates of overclassification per image and per time-step which rendered the outputs incomparable over time. Therefore using the Landsat series to examine

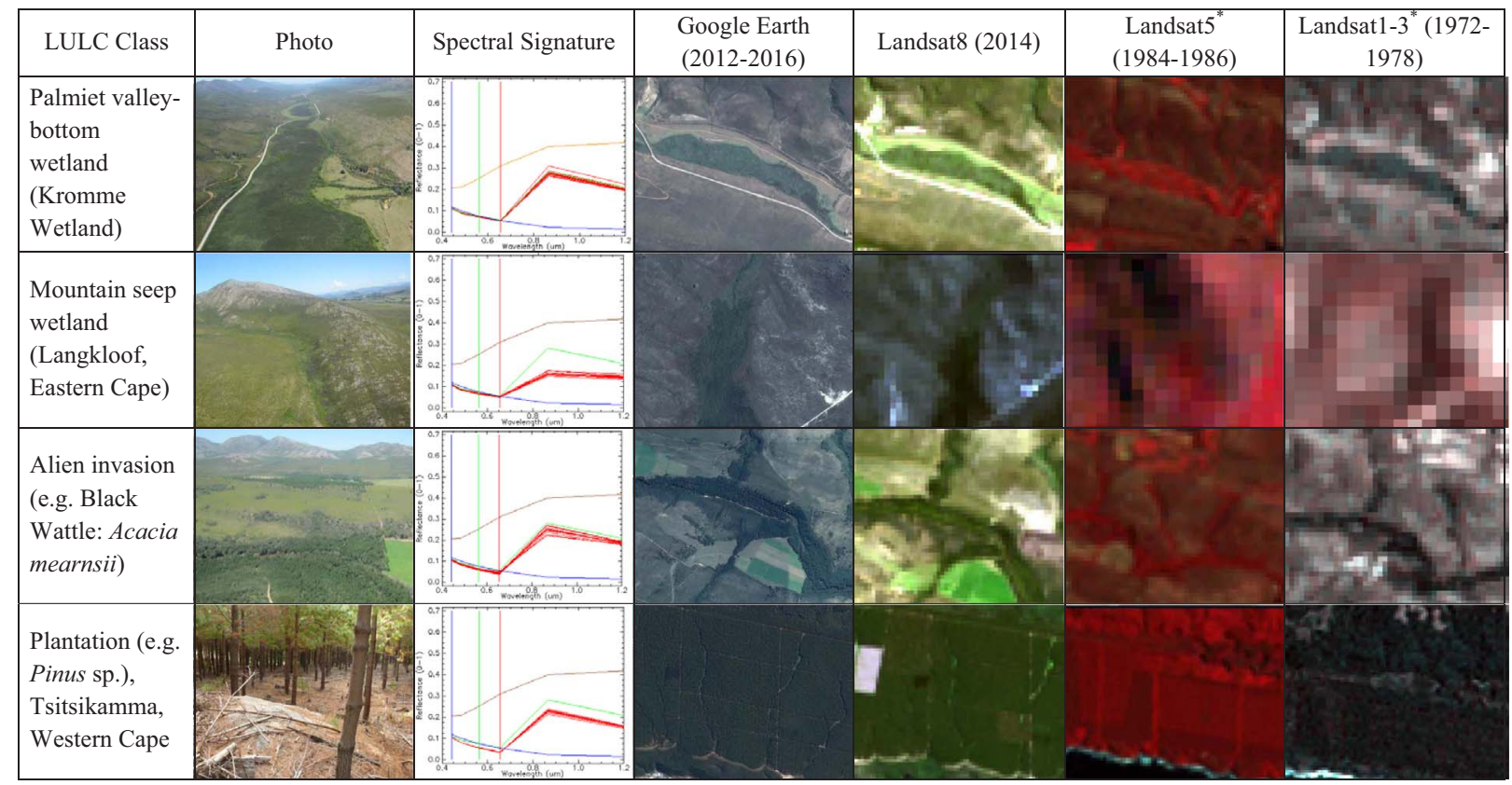

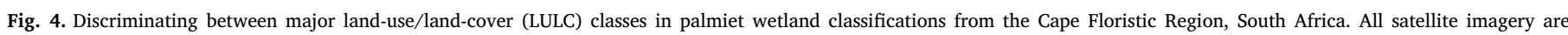

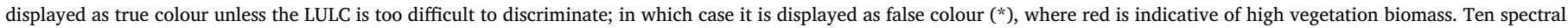

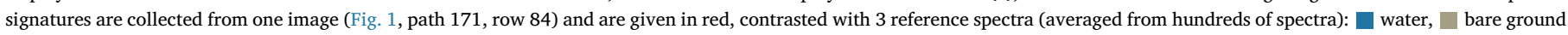
and palmiet. Two sets of spectra are given for agriculture: representing two main different types (orchards and fodder crops).,. 


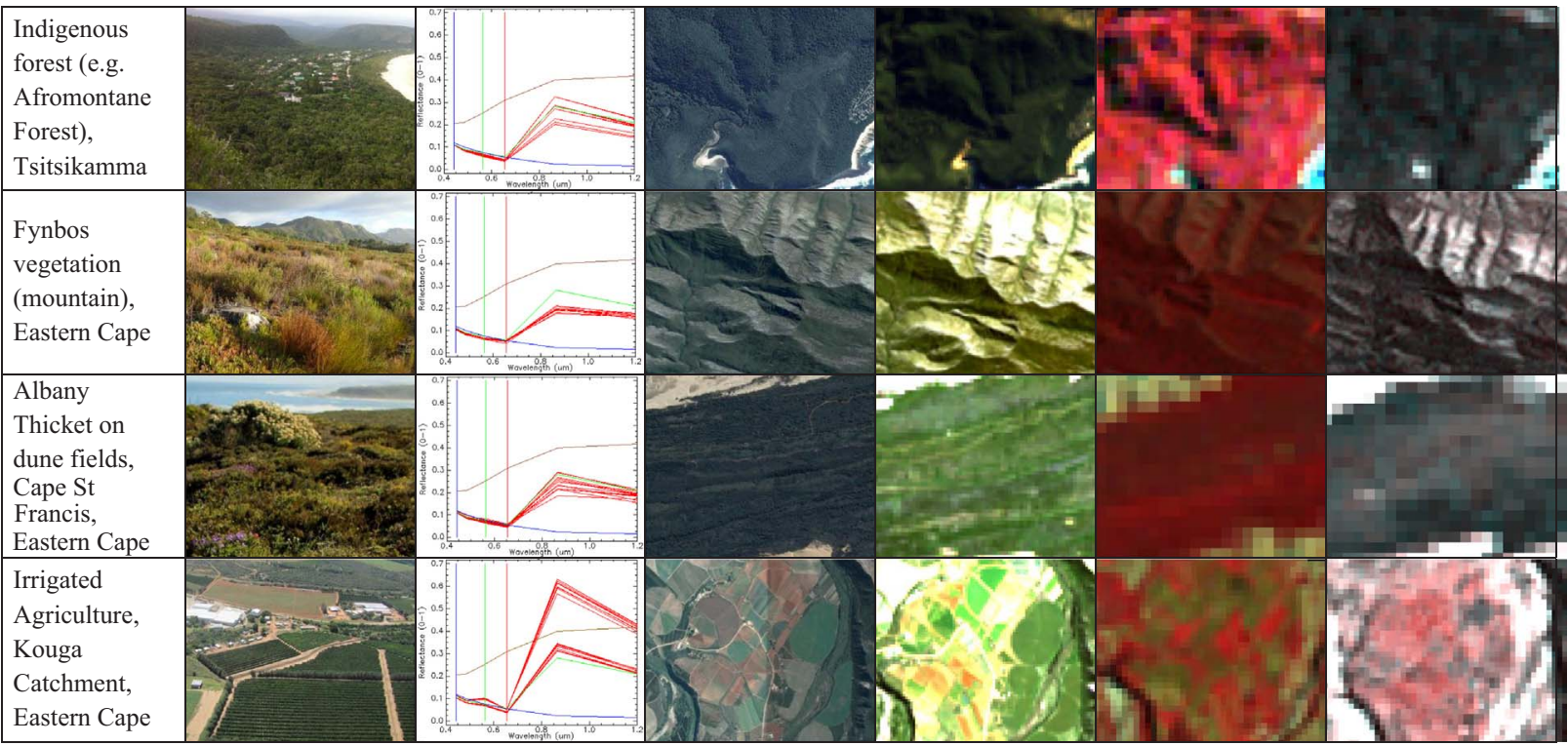

Fig. 4. (continued)

change of small wetlands over time was unsuccessful in this study. Other studies have also found aerial photographs to deliver a superior product relative to multispectral imagery (Harvey and Hill, 2001). This is in contrast to studies using the Landsat series to classify larger wetland areas, which are often more successful (Han et al., 2015; MacAlister and Mahaxay, 2009).

We therefore used historical aerial photograph digitization for the eight palmiet wetland fragments to accurately examine change in wetland extent over time -since the 1940s. However we realised that some of the damage to these wetlands had been done before the first aerial photographs had been taken (pre-1940s). To understand wetland dynamics and to form restoration targets, it is essential to understand original wetland extent, and their original hydrological classification: whether these wetlands were originally channelled or unchannelled valley-bottom wetlands (although see argument of Grenfell et al. (2009). Therefore it was essential to have some information on where these wetlands may once have occurred, and to have an idea of their original extent. To that end we performed predictive modelling
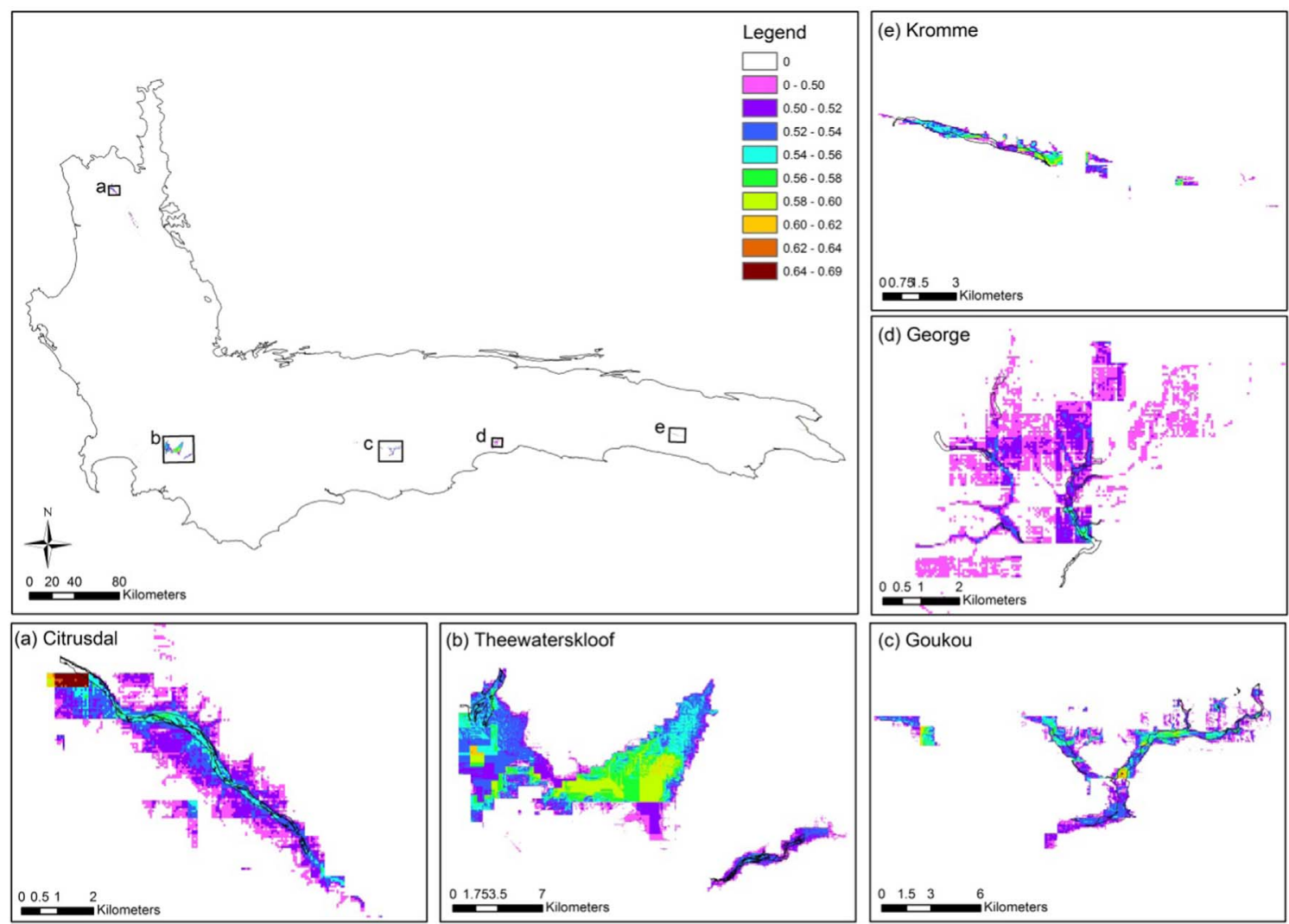

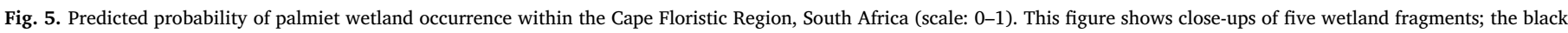

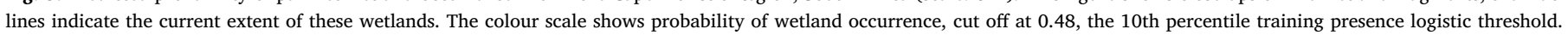


Table 3

Cumulative percentage contribution of environmental variables to the prediction of palmiet wetland occurrence in the CFR, South Africa. Thresholds are based on cumulative response curves.

\begin{tabular}{|c|c|c|}
\hline Environmental variable & Contribution (\%) & Thresholds \\
\hline Groundwater depth (mamsl) & 22.1 & > 300mamsl (35\%) \\
\hline Altitude (DEM) & 43.4 & $\begin{array}{l}<400 \mathrm{~m}(100 \%) ;<100 \\
(50 \%)\end{array}$ \\
\hline $\begin{array}{l}\text { Mean diurnal temperature range } \\
\text { (mean of monthly) }\end{array}$ & 60.4 & $>11.5{ }^{\circ} \mathrm{C}(35 \%)$ \\
\hline Groundwater recharge (mm/a) & 68.4 & $50-150 \mathrm{~mm}(26-36 \%)$ \\
\hline $\begin{array}{l}\text { Precipitation of driest quarter } \\
\quad(\mathrm{mm})\end{array}$ & 75.9 & $<80 \mathrm{~mm}(56 \%)$ \\
\hline Slope (degrees) & 80.3 & $-5-18^{\circ}(18-36 \%)$ \\
\hline Mean annual runoff (mm) & 83.4 & $>100 \mathrm{~mm}(36 \%)$ \\
\hline Borehole yield $(1 / \mathrm{s})$ & 86.2 & $>81 / \mathrm{s}(36 \%)$ \\
\hline $\begin{array}{l}\text { Max temperature of warmest } \\
\text { month }\left({ }^{\circ} \mathrm{C}\right)\end{array}$ & 88.7 & $24-36^{\circ} \mathrm{C}(35 \%)$ \\
\hline $\begin{array}{l}\text { Min temperature of coldest } \\
\text { month }\left({ }^{\circ} \mathrm{C}\right)\end{array}$ & 90.2 & $4-7{ }^{\circ} \mathrm{C}(20-45 \%)$ \\
\hline
\end{tabular}

(MaxEnt) using the input data from the aerial photograph analysis. We found that this modelling technique was not optimal for mapping historical extent of palmiet wetlands, probably due to the low resolution of some of the predictors available. Overall, the best technique for small wetland detection, extent mapping and analysing temporal changes proved to be a combination of multispectral remote-sensing and aerial photograph analysis.

\subsection{Implications for management, rehabilitation and conservation}

The outlook for palmiet wetlands in the CFR is not positive. Existing wetlands have declined by on average $31 \%$ since the 1940 's, although we have little information on the original extent of these wetlands. Nel and Driver (2012) estimate that over 50\% of South African wetlands have been lost. This is slightly lower than the global average of $64-71 \%$ (Gardner et al., 2015). It is also important to note that the quality of these valley-bottom palmiet wetlands has declined over the past $60-70$ years, becoming increasingly fragmented and channelized. According to the analysis of major drivers, this is largely due to roads bisecting and destabilizing the alluvium of the wetlands, causing headcut erosion and eventually channelization of these typically unchannelled systems. Similar causes of wetland degradation, wagon tracks and roads, in the Karoo have been deduced (Boardman, 2014). Hydraulic changes to these wetland systems by erosion are by far the most severe type of degradation and are difficult and expensive to rehabilitate (Grenfell et al., 2009). By draining the wetlands, these hydraulic changes also facilitate the invasion by alien species, often trees, which further perpetuates the cycle of degradation. Agriculture either alongside the wetland, or on the alluvium itself, poses another great threat to wetland integrity.

In terms of implications for management, degradation caused by roads or other infrastructure bisecting palmiet wetlands mostly took place before the 1980s. In the South African case, it is unlikely that more roads will be constructed through or over these wetlands. However for other valley-bottom wetlands globally, it is recommended that disturbance of the wetland should be avoided at all costs, and where possible bridges should be constructed, with high clearance and no culverts or obstructions beneath. Provision is made for protection of wetlands in the case of road construction in South Africa in two main ways: through compliance with section 24(7) of NEMA (environmental impact assessment required) and through the National Water Act 36 of 1998 (NWA) which requires a water-use licence if the flow of water is diverted. Perhaps of greater concern currently, is the management of agriculture encroaching on or into palmiet wetlands, or of drainage canals being dug for agriculture. These practises are still continuing at present, and should be monitored and prevented, in accordance with the National Environmental Management Act 107 of 1998 (NEMA), the National Water Act and the Conservation of Agricultural Resources Act (CARA).

One important observation that was made during the historical mapping is that palmiet wetlands seem to be remarkably stable over periods of up to 70 years, unless the alluvium is destabilized, in which case headcut erosion takes place rapidly. In case 1 (Fig. 7), a road bisecting the top end of the palmiet wetland, the point at which a steep mountain stream becomes unconfined and enters a broader valley bottom, caused a knick-point, resulting in channel erosion. This channel

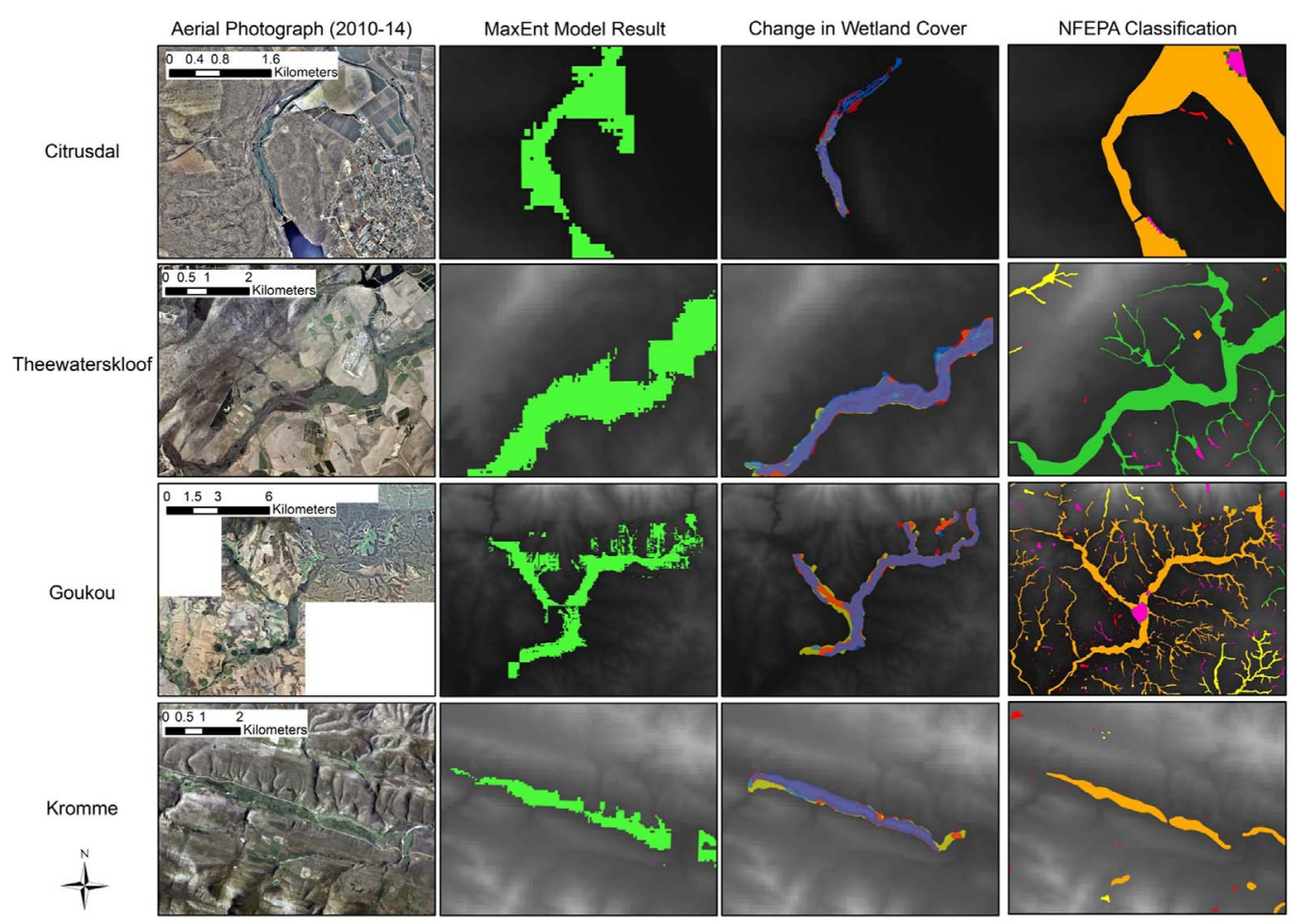

Fig. 6. Comparison of aerial photograph and MaxEnt model output to an existing South African wetland product used for management and conservation (NFEPA) for four palmiet wetland sites in the Cape Floristic Region of South Africa. Change in wetland cover is shown by displaying the aerial photograph analysis results for: 1940/50s, 1980s and 2010s. The NFEPA Classification has five different categories shown here: channelled valleybottom wetland, flat, floodplain wetland, seep, and unchannelled valleybottom wetland. 
Table 4

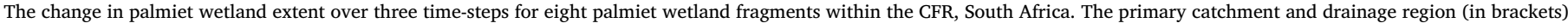
are given. A negative change indicates an increase in area and positive a decrease. Letters in the bottom row denote significance of differences for the total change.

\begin{tabular}{|c|c|c|c|c|c|}
\hline \multirow[b]{2}{*}{ Location } & \multirow[b]{2}{*}{ Catchment } & \multicolumn{4}{|c|}{ Palmiet wetland extent $\left(\mathrm{km}^{2}\right)$} \\
\hline & & $1940 / 50 \mathrm{~s}$ & $1980 \mathrm{~s}$ & 2010s & Change (\%) \\
\hline \multirow[t]{2}{*}{ Citrusdal } & Berg Catchment (G) & 0.18 & 0.26 & 0.27 & $-0.09(51 \%)$ \\
\hline & & 1.26 & 1.23 & 1.26 & $0.00(0.2 \%)$ \\
\hline \multirow[t]{2}{*}{ Theewaterskloof } & Breede Catchment $(\mathrm{H})$ & 4.24 & 3.64 & 2.43 & $1.81(43 \%)$ \\
\hline & & 2.21 & 2.14 & 2.00 & $0.21(9 \%)$ \\
\hline Duivenhoks & & 1.16 & 0.68 & 0.52 & $0.64(55 \%)$ \\
\hline Goukou & & 8.44 & 6.67 & 5.80 & $2.64(31 \%)$ \\
\hline George & Tsitsikamma Catchment (K) & 1.56 & 0.84 & 0.73 & $0.83(53 \%)$ \\
\hline Kromme & & 1.52 & 1.13 & 1.19 & $0.33(22 \%)$ \\
\hline Total & & $20.57^{\mathrm{a}}$ & $16.58^{\mathrm{ab}}$ & $14.21^{\mathrm{b}}$ & $6.36(31 \%)$ \\
\hline
\end{tabular}

Table 5

Main drivers of palmiet wetland change within the CFR, South Africa. The percentages indicate the relative importance of each driver in terms of the frequency with which it is recorded in the study wetlands.

\begin{tabular}{ll}
\hline Drivers & Contribution (\%) \\
\hline Roads bisecting wetland & 28.6 \\
Irrigated agriculture & 25.0 \\
Alien plant invasion & 21.4 \\
Dams & 14.3 \\
Water canals & 10.7 \\
\hline
\end{tabular}

is on average $10 \mathrm{~m}$ wide and 3-4 m deep. Between 2004 and 2014 the channel had lengthened by $446.24 \mathrm{~m}$, an average of $45 \mathrm{~m}$ per year. According to historical imagery available on Google Earth Pro, the change is not gradual, year-by-year, but rather as the result of extreme flood events, which happen on average once a decade. In case 2 , the stability of palmiet wetland systems is demonstrated. This channel, whether natural or man-made, has remained open in this palmiet wetland for the past 60 years, demonstrating that once these systems reach an equilibrium, they are highly stable over time. Similar observations were made in a geomorphological study of the Goukou palmiet wetland system, where sections of the wetland were found to be remarkably stable between 1941 and 1991 (Job, 2014). This has important management and rehabilitation implications, as it means that once damage has occurred, causing a knick-point, it should be rehabilitated before the next large 10-year floods occur, otherwise substantial wetland loss is risked. Therefore timing is critical in these rehabilitation projects. Ultimately as these wetlands become channelized and the alluvium and peat is washed away, valuable ecosystem services are lost (Rebelo et al., 2015)

Lastly, it is apparent that palmiet wetlands are not adequately represented in the South African National Freshwater Ecosystem Priority Areas (NFEPA) Atlas. Many of these palmiet wetlands are misclassified, and there is no information available on the condition of these wetlands. Many are degraded or no longer exist, and yet are indicated as wetlands in the atlas. Similar results were found in a congruency assessment between the South African National Wetland Map and two sites which had wetlands mapped on 1:10 000 aerial photographs: the Overberg Municipal District and the City of Cape Town (CoCT) Metro (van Deventer et al., 2016). The data from small scale studies such as this one, can be used to supplement coarser national-scale wetland inventories, improving the knowledge of wetland distribution, type and condition. This is essential for prioritizing wetland rehabilitation and conservation. At least half of the eight wetlands which were chosen for wetland change analysis are in a critical condition, threatened by headcut erosion. If steps are not taken immediately to stop this erosion, it is likely that these wetlands will be drained or lost in the next 50 years. Most of these palmiet wetlands are underlain by peatbeds, known to have important water purification abilities (Rebelo, 2017). Additionally many of these wetlands are located above dams, providing municipal water to millions of South Africans. If these wetlands are lost or become degraded, there is likely to be an impact on the water quality of these important regional water resources.

\subsection{Conclusion}

Historical aerial photograph analysis showed that South African palmiet wetlands are in decline, and due to drivers such as erosion, agriculture and alien plant invasion, are becoming increasingly

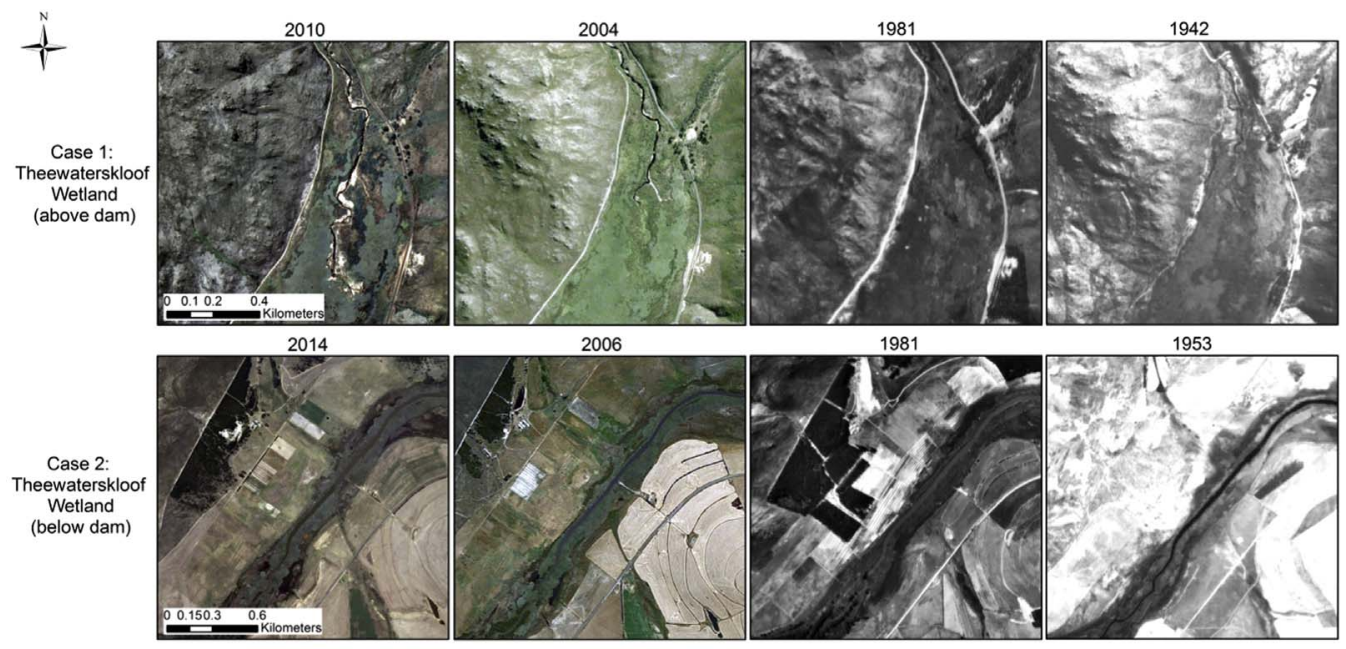

Fig. 7. Wetland change over time: two interesting cases in point, illustrated over four time-steps for the last $61-68$ years. The first wetland is the upper Theewaterskloof wetland, and the second is the lower Theewaterskloof wetland, above and below the municipal dam respectively, in the Cape Floristic Region, South Africa. The first case shows the progression of a head-cut through the wetland, and the second shows the persistence of a channel. It is unknown whether this is man-made or natural. 
degraded and fragmented. Structural wetland rehabilitation to stop the progression of gully erosion is recommended prior to the next large respective local flood events, to prevent substantial loss and high rehabilitation costs. The comparison of three techniques to detect and map extent of small wetlands demonstrated that a combination of techniques yields the best results. We found classification of Landsat8 imagery to be the most successful technique for initial wetland detection, which can be refined using aerial photographs where greater accuracy is needed. This addresses a major challenge in mapping small wetlands at a landscape level.

\section{Acknowledgements}

A.J.R. gratefully acknowledges the following organizations for funding: The Erasmus Mundus Programme (European Commission), Applied Centre for Climate and Earth System Science (ACCESS) Project Funding and GreenMatter, South Africa. The authors wish to thank Guy Thoonen for extensive assistance with analysis of Landsat Imagery and Stef Lhermitte for help with batch processing Landast8 images from DN to reflectance. We thank the reviewers for useful suggestions which improved the manuscript.

\section{Appendix A}

see Tables $\mathrm{A} 1$ and $\mathrm{A} 2$

Table A1

Friginal MaxEnt model input variables for consideration, their labels, units, data type, cell size, file type and source.

\begin{tabular}{|c|c|c|c|c|c|c|c|c|}
\hline Variable type & Variable & Label & Units & Data Type & Cell size & Extent & File & Source \\
\hline \multirow[t]{11}{*}{ Climate } & Annual Mean Temperature & bio1 & ${ }^{\circ} \mathrm{C} * 10$ & Continuous & $0.8 \mathrm{~km}$ & Global & raster & WorldClim $^{\mathrm{a}}$ \\
\hline & $\begin{array}{l}\text { Mean Diurnal Range (Mean of monthly (max temp - min } \\
\text { temp)) }\end{array}$ & bio2 & ${ }^{\circ} \mathrm{C} * 10$ & Continuous & $0.8 \mathrm{~km}$ & Global & raster & WorldClim $^{\mathrm{a}}$ \\
\hline & Isothermality $(* 100)$ & bio3 & ${ }^{\circ} \mathrm{C}^{*} 10$ & Continuous & $0.8 \mathrm{~km}$ & Global & raster & WorldClim $^{\mathrm{a}}$ \\
\hline & Temperature Seasonality (stdev*100) & bio4 & ${ }^{\circ} \mathrm{C} * 10$ & Continuous & $0.8 \mathrm{~km}$ & Global & raster & WorldClim $^{\mathrm{a}}$ \\
\hline & Max Temp. of Warmest Month & bio5 & ${ }^{\circ} \mathrm{C}^{*} 10$ & Continuous & $0.8 \mathrm{~km}$ & Global & raster & WorldClim $^{\mathrm{a}}$ \\
\hline & Min Temp. of Coldest Month & bio6 & ${ }^{\circ} \mathrm{C} * 10$ & Continuous & $0.8 \mathrm{~km}$ & Global & raster & WorldClim $^{\mathrm{a}}$ \\
\hline & Temperature Annual Range & bio7 & ${ }^{\circ} \mathrm{C} * 10$ & Continuous & $0.8 \mathrm{~km}$ & Global & raster & WorldClim $^{\mathrm{a}}$ \\
\hline & Mean Temp of Wettest Quarter & bio8 & ${ }^{\circ} \mathrm{C}^{*} 10$ & Continuous & $0.8 \mathrm{~km}$ & Global & raster & WorldClim $^{\mathrm{a}}$ \\
\hline & Mean Temp of Driest Quarter & bio9 & ${ }^{\circ} \mathrm{C}^{*} 10$ & Continuous & $0.8 \mathrm{~km}$ & Global & raster & WorldClim $^{\mathrm{a}}$ \\
\hline & Mean Temp of Warmest Quarter & bio10 & ${ }^{\circ} \mathrm{C} * 10$ & Continuous & $0.8 \mathrm{~km}$ & Global & raster & WorldClim $^{\mathrm{a}}$ \\
\hline & Mean Temp of Coldest Quarter & bio11 & ${ }^{\circ} \mathrm{C}^{*} 10$ & Continuous & $0.8 \mathrm{~km}$ & Global & raster & WorldClim $^{\mathrm{a}}$ \\
\hline \multirow[t]{9}{*}{ Hydrology } & Annual Precipitation & bio12 & $\mathrm{mm}$ & Continuous & $0.8 \mathrm{~km}$ & Global & raster & WorldClim $^{\mathrm{a}}$ \\
\hline & Precipitation of Wettest Month & bio13 & $\mathrm{mm}$ & Continuous & $0.8 \mathrm{~km}$ & Global & raster & WorldClim $^{\mathrm{a}}$ \\
\hline & Precipitation of Driest Month & bio14 & $\mathrm{mm}$ & Continuous & $0.8 \mathrm{~km}$ & Global & raster & WorldClim $^{\mathrm{a}}$ \\
\hline & Precipitation Seasonality (Coefficient of Variation) & bio15 & $\mathrm{mm}$ & Continuous & $0.8 \mathrm{~km}$ & Global & raster & WorldClim $^{\mathrm{a}}$ \\
\hline & Precipitation of Wettest Quarter & bio16 & $\mathrm{mm}$ & Continuous & $0.8 \mathrm{~km}$ & Global & raster & WorldClim $^{\mathrm{a}}$ \\
\hline & Precipitation of Driest Quarter & bio17 & $\mathrm{mm}$ & Continuous & $0.8 \mathrm{~km}$ & Global & raster & WorldClim $^{\mathrm{a}}$ \\
\hline & Precipitation of Warmest Quarter & bio18 & $\mathrm{mm}$ & Continuous & $0.8 \mathrm{~km}$ & Global & raster & WorldClim $^{\mathrm{a}}$ \\
\hline & Precipitation of Coldest Quarter & bio19 & $\mathrm{mm}$ & Continuous & $0.8 \mathrm{~km}$ & Global & raster & WorldClim $^{\mathrm{a}}$ \\
\hline & Mean annual runoff & bio20 & $\mathrm{mm}$ & Continuous & $1.6 \mathrm{~km}$ & RSA & raster & SWSA \\
\hline \multirow[t]{4}{*}{ Groundwater } & Groundwater recharge & bio21 & $\mathrm{mm} / \mathrm{a}$ & Continuous & $0.8 \mathrm{~km}$ & RSA & raster & GR2, GEOSS, SARVA \\
\hline & Groundwater electrical conductivity & bio22 & $\mathrm{mS} / \mathrm{m}$ & Continuous & $46 \mathrm{~m}$ & RSA & raster & GR2, GEOSS, SARVA \\
\hline & Borehole yield & bio23 & $1 / \mathrm{s}$ & Continuous & $46 \mathrm{~m}$ & RSA & raster & GR2, GEOSS, SARVA \\
\hline & Depth to groundwater & bio24 & (mamsl) & Continuous & $0.8 \mathrm{~km}$ & RSA & raster & GR2, GEOSS, SARVA \\
\hline \multirow[t]{2}{*}{ Geology \& Soils } & Geology & bio25 & - & Categorical & $0.5 \mathrm{~km}$ & RSA & raster & WR90 \\
\hline & Soils & bio26 & - & Categorical & $0.5 \mathrm{~km}$ & RSA & raster & WR90 \\
\hline \multirow[t]{5}{*}{ Digital elevation model derived } & Altitude (dem) & bio29 & $\mathrm{m}$ amsl & Continuous & $46 \mathrm{~m}$ & CFR & raster & 90 m SRTM DEM \\
\hline & Slope & bio30 & Degrees & Continuous & $46 \mathrm{~m}$ & CFR & raster & 90 m SRTM DEM \\
\hline & Aspect & bio31 & Degrees & Continuous & $46 \mathrm{~m}$ & CFR & raster & 90 m SRTM DEM \\
\hline & Flow accumulation & bio32 & - & Continuous & $46 \mathrm{~m}$ & CFR & raster & 90 m SRTM DEM \\
\hline & Flow direction & bio33 & Degrees & Categorical & $46 \mathrm{~m}$ & CFR & raster & 90 m SRTM DEM \\
\hline \multirow[t]{2}{*}{ Biotic } & Palmiet wetland occurrence data & & Presence & & & & point & \\
\hline & Background File & & Presence & Absence & & & point & \\
\hline
\end{tabular}

${ }^{\text {a }}$ Hijmans, R.J., S.E. Cameron, J.L. Parra, P.G. Jones and A. Jarvis, 2005. Very high resolution interpolated climate surfaces for global land areas. International Journal of Climatology 25: $1965-1978$

Table A2

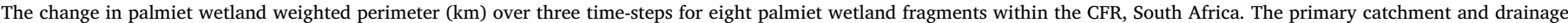
region (in brackets) are given. All wetlands show an increase in weighted perimeter (negative change). Letters denote significance of differences of the totals.

\begin{tabular}{|c|c|c|c|c|c|}
\hline Wetland Location & Catchment & $1940 / 50$ 's & 1980's & 2010's & Change (\%) \\
\hline \multirow[t]{2}{*}{ Citrusdal } & \multirow[t]{2}{*}{ Berg Catchment (G) } & 48.51 & 46.27 & 78.78 & $-30.27(38 \%)$ \\
\hline & & 33.58 & 39.26 & 37.98 & $-4.40(11 \%)$ \\
\hline \multirow[t]{2}{*}{ Theewaterskloof } & \multirow[t]{4}{*}{ Breede Catchment $(\mathrm{H})$} & 9.81 & 11.73 & 14.86 & $-5.05(34 \%)$ \\
\hline & & 17.45 & 16.07 & 28.73 & $-11.28(39 \%)$ \\
\hline Duivenhoks & & 45.33 & 44.19 & 68.21 & $-22.87(34 \%)$ \\
\hline Goukou & & 7.54 & 9.74 & 9.88 & $-2.35(24 \%)$ \\
\hline George & \multirow[t]{3}{*}{ Tsitsikamma Catchment (K) } & 27.59 & 32.79 & 34.72 & $-7.13(21 \%)$ \\
\hline Kromme & & 11.41 & 14.92 & 12.10 & $-0.70(5 \%)$ \\
\hline Total & & $201.22^{\mathrm{a}}$ & $214.96^{\mathrm{a}}$ & $285.26^{b}$ & $-84.04(29 \%)$ \\
\hline
\end{tabular}



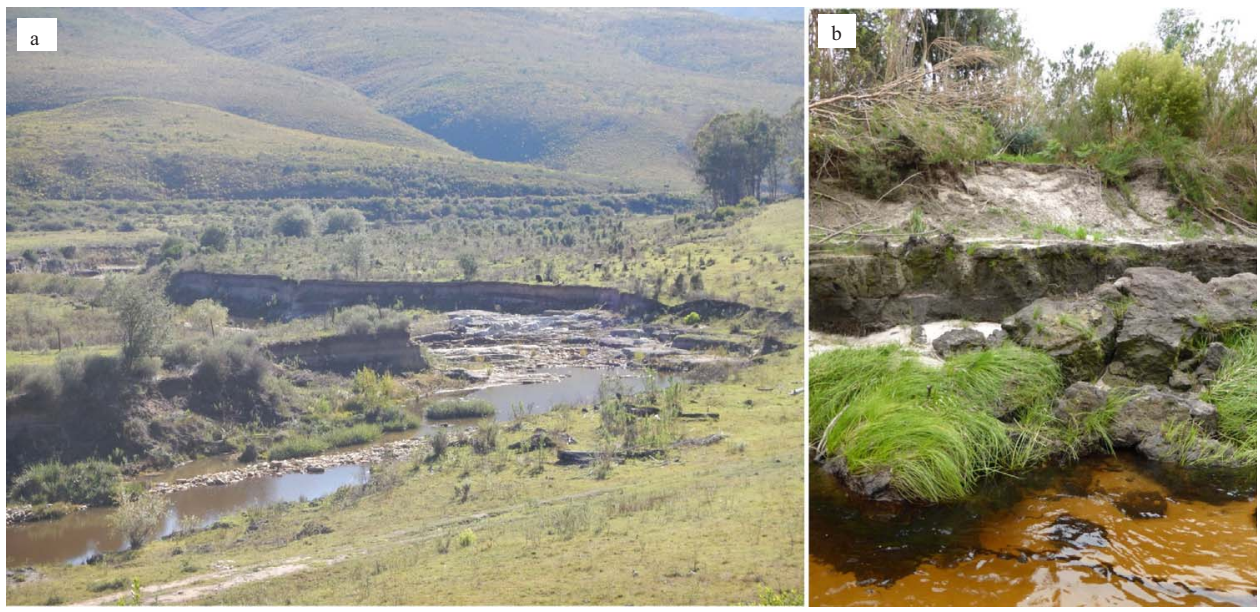

Plate A1. Photographs showing channel/gulley erosion in the Kromme (a) and Theewaterskloof (b). In the Kromme, the floodwaters have eroded the valley-bottom down to the bedrock which is visible on the floor of the valley. The knick-point for the erosion in both cases is located to the left (not pictured). Once this erosion begins, it is very difficult for the system to recover, and active rehabilitation is necessary.

\section{References}

Asadzadeh, S., de Souza Filho, C., 2016. A review on spectral processing methods for geological remote sensing. Int. J. Appl. Earth Obs. Geoinf. 47, 69-90.

Boardman, J., 2014. How old are the gullies (dongas) of the Sneeuberg uplands, Eastern Karoo, South Africa? Catena 113, 79-85. http://dx.doi.org/10.1016/j.catena.2013. 09.012.

CBD, 1992. Convention on Biological Diversity.

Chang, C., Lin, C., 2011. LIBSVM: a library for support vector machines. ACM Trans Intell. Syst. Technol. 2 (3), 1-27.

Cowling, R., Pressey, R., Rouget, M., Lombard, A.T., 2003. A conservation plan for a global biodiversity hotspot-the Cape Floristic Region, South Africa. Biol. Conserv. 112, 191-216. http://dx.doi.org/10.1016/S0006-3207(02)00425-1.

Cowling, R.M., Heijnis, C.E., 2001. The identification of broad habitat units as biodiversity entities for a systematic conservation planning in the Cape Floristic Region. South Afr. J. Bot. 67, 15-38.

Driver, A., Sink, K.J., Nel, J.N., Holness, S., Van Niekerk, L., Daniels, F., Jonas, Z., Majiedt, P.A., Harris, L., Maze, K., 2012. National Biodiversity Assessment 2011: An assessment of South Africa's biodiversity and ecosystems. Pretoria.

Gala, T.S., Melesse, A.M., 2012. Monitoring prairie wet area with an integrated LANDSAT ETM + , RADARSAT-1 SAR and ancillary data from LIDAR. Catena 95, 12-23. http:// dx.doi.org/10.1016/j.catena.2012.02.022.

Gardner, R.C., Barchiesi, S., Beltrame, C., Finlayson, C.M., Galewski, T., Harrison, I., Paganini, M., Perennou, C., Pritchard, D.E., Rosenqvist, A., Walpole, M., 2015. State of the World 's Wetlands and their Services to People : A compilation of recent analyses. Ramsar Brief. Note no. 7, 1-20. doi:10.2139/ssrn.2589447.

Glowka, L., Burhenne-Guilmin, F., Synge, H., 1994. A guide to the Convention on Biological Diversity, Iucn. doi:10.1111/j.1461-0248.2005.00841.x.

Grenfell, M.C., Ellery, W.N., Grenfell, S.E., 2009. Valley morphology and sediment cascades within a wetland system in the KwaZulu-Natal Drakensberg Foothills, Eastern South Africa. Catena 78, 20-35. http://dx.doi.org/10.1016/j.catena.2009.02.004.

Han, X., Chen, X., Feng, L., 2015. Remote Sensing of Environment Four decades of winter wetland changes in Poyang Lake based on Landsat observations between 1973 and 2013. Remote Sens. Environ. 156, 426-437. http://dx.doi.org/10.1016/j.rse.2014. 10.003.

Harvey, K.R., Hill, G.J.E., 2001. Vegetation mapping of a tropical freshwater swamp in the Northern Territory, Australia: a comparison of aerial photography, Landsat TM and spot satellite imagery. Int. J. Remote Sens. 22, 2911-2925. http://dx.doi.org/10. 1080/01431160119174.

Hiestermann, J., Rivers-Moore, N., 2015. Predictive modelling of wetland occurrence in KwaZulu-Natal, South Africa. S. Afr. J. Sci. 111, 1-10. http://dx.doi.org/10.17159/ sajs.2015/20140179.

Holmes, P., Pugnalin, A., 2016. The biodiversity network for the Cape Town municipal area C-plan \& MARXAN analysis: 2016 methods \& results. City Cape Town.

Hunter, E.A., Raney, P.A., Gibbs, J.P., Leopold, D.J., 2012. Improving wetland mitigation site identification through community distribution modeling and a patch-based ranking scheme. Wetlands 32, 841-850. http://dx.doi.org/10.1007/s13157-012 0315-7.

Job, N., 2014. Geomorphic Origin and Dynamics of Deep, Peat-filled, Valley Bottom Wetlands Dominated by Palmiet (Prionium serratum) - A Case Study Based on the Goukou Wetland, Western Cape. Rhodes University, Eastern Cape.

Kameyama, S., Yamagata, Y., Nakamura, F., Kaneko, M., 2001. Development of WTI and turbidity estimation model using SMA - application to Kushiro Mire, eastern Hokkaido, Japan. Remote Sens. Environ. 77, 1-9. http://dx.doi.org/10.1016/S00344257(01)00189-4.

Knight, A.W., Tindall, D.R., Wilson, B.A., 2009. A multitemporal multiple density slice method for wetland mapping across the state of Queensland, Australia. Int. J. Remote Sens. 30, 3365-3392. http://dx.doi.org/10.1080/01431160802562180.

Landmann, T., Schramm, M., Colditz, R.R., Dietz, A., Dech, S., 2010. Wide area wetland mapping in semi-arid Africa using 250-meter MODIS metrics and topographic variables. Remote Sens. 2, 1751-1766. http://dx.doi.org/10.3390/rs2071751.

Li, J., Chen, W., 2005. A rule-based method for mapping Canada's wetlands using optical, radar and DEM data. Int. J. Remote Sens. 26, 5051-5069. http://dx.doi.org/10.1080/ 01431160500166516.

MacAlister, C., Mahaxay, M., 2009. Mapping wetlands in the Lower Mekong Basin for wetland resource and conservation management using Landsat ETM images and field survey data. J. Environ. Manag. 90, 2130-2137. http://dx.doi.org/10.1016/j. jenvman.2007.06.031.

Merow, C., Smith, M.J., Silander, J.A., 2013. A practical guide to MaxEnt for modeling species' distributions: What it does, and why inputs and settings matter. Ecography 36, 1058-1069. http://dx.doi.org/10.1111/j.1600-0587.2013.07872.x.

Midgley, G.F., Hannah, L., Millar, D., Thuiller, W., Booth, A., 2003. Developing regional and species-level assessments of climate change impacts on biodiversity in the Cape Floristic Region. Biol. Conserv. 112, 87-97. http://dx.doi.org/10.1016/S00063207(02)00414-7.

Mitsch, W.J., Gossilink, J.G., 2000. The value of wetlands: importance of scale and landscape setting. Ecol. Econ. 35, 25-33. http://dx.doi.org/10.1016/S0921-8009(00) 00165-8.

Mittermeier, R., Turner, W., Larsen, F., Brooks, T., Gascon, C., 2011. Global biodiversity conservation: the critical role of hotspots. In: Zachos, F., J.C., H. (Eds.), Biodiversity Hotspots: Distribution and Protection of Conservation Priority Areas. Springer, Berlin Heidelberg, pp. 3-22.

Myers, N., Mittermeier, R.A., Mittermeier, C.G., da Fonseca, G.A., Kent, J., 2000. Biodiversity hotspots for conservation priorities. Nature 403, 853-858. http://dx.doi. org $/ 10.1038 / 35002501$.

Nel, J., Driver, A., Strydom, W., Maherry, A., Petersen, C., Hill, L., Roux, D., Nienaber, S. van Deventer, H., Swartz, E., Smith-Adao, L., 2011. Atlas of Freshwater Ecosystem Priority Areas in South Africa: Maps to support sustainable development of water resources WRC Report No. TT 500/11.

Nel, J.L., Driver, A., 2012. Volume 2: Freshwater Component.

Nsor, A.C., 2007. Plant Community Distribution and Diversity, and Threats to Vegetation of the Kromme River Peat Basins, Eastern Cape Province, South Africa. M.Sc. Thesis. Rhodes University.

Ozesmi, S.L., Bauer, M.E., 2002. Satellite remote sensing of wetlands. Wetl. Ecol. Manag. 10, 381-402. http://dx.doi.org/10.1023/A:1020908432489.

Phillips, S.B., Aneja, V.P., Kang, D., Arya, S.P., 2006. Modelling and analysis of the atmospheric nitrogen deposition in North Carolina. Int. J. Glob. Environ. Issues 6 , 231-252. http://dx.doi.org/10.1016/j.ecolmodel.2005.03.026.

Ramsar, 1971. Convention on Wetlands of International Importance especially as Waterfowl Habitat. Ramsar (Iran), 2 February 1971. UN Treaty Series No. 14583. As amended by the Paris Protocol, 3 December 1982, and Regina Amendments, 28 May 1987.

Rebelo, A., Holmes, P., Dorse, C., Wood, J., 2011. Impacts of urbanization in a biodiversity hotspot: conservation challenges in Metropolitan Cape Town. South Afr. J. Bot. 77, 20-35.

Rebelo, A.G., Siegfried, W.R., 1992. Where should nature reserves be located in the Cape Floristic Region, South Africa? Models for the spatial configuration of a reserve network aimed at maximizing the protection of floral diversity. Conserv. Biol. 6 , 243-252.

Rebelo, A.J., 2017. Ecosystem Services of Palmiet Wetlands: The Role of Ecosystem Composition \& Function. University of Antwerp (Belgium), Stellenbosch University (South Africa).

Rebelo, A.J., Le Maitre, D.C., Esler, K.J., Cowling, R.M., 2015. Hydrological responses of a valley-bottom wetland to land-use/land-cover change in a South African catchment: making a case for wetland restoration. Restor. Ecol. 23, 829-841. http://dx.doi.org/ 10.1111/rec.12251.

Rebelo, L.M., Finlayson, C.M., Nagabhatla, N., 2009. Remote sensing and GIS for wetland inventory, mapping and change analysis. J. Environ. Manag. 90, 2144-2153. http:// dx.doi.org/10.1016/j.jenvman.2007.06.027. 
Rountree, M., Thompson, M., Kotze, D., Batchelor, A., Marneweck, G., 2009. WETPrioritise: Guidelines for prioritising wetlands at national, regional and local scales. Pretoria.

Russi, D., ten Brink, P., Farmer, A., Badura, T., Coates, D., Förster, J., Kumar, R. Davidson, N., 2013. The Economics of Ecosystems and Biodiversity for Water and Wetlands. IEEP, London and Brussels; Ramsar Secretariat, Gland.

Schölkopf, B., Smola, A., Williamson, R., Bartlett, P., 2000. New support vector algorithms. Neural Comput. 12, 1207-1245.

Simonit, S., Perrings, C., 2011. Sustainability and the value of the "regulating" services: wetlands and water quality in Lake Victoria. Ecol. Econ. 70, 1189-1199. http://dx. doi.org/10.1016/j.ecolecon.2011.01.017.

Skead, C., 2009. Historical plant incidence in southern Africa; Strelitzia 24. Pretoria, South Africa.

Thomas, R.F., Kingsford, R.T., Lu, Y., Cox, S.J., Sims, N.C., Hunter, S.J., 2015. Mapping inundation in the heterogeneous floodplain wetlands of the Macquarie Marshes, using Landsat Thematic Mapper. J. Hydrol. 524, 194-213. http://dx.doi.org/10. 1016/j.jhydrol.2015.02.029.

van Deventer, H., Nel, J., Mbona, N., Job, N., Ewart-Smith, J., Snaddon, K., Maherry, A. 2016. Desktop classification of inland wetlands for systematic conservation planning in data-scarce countries: mapping wetland ecosystem types, disturbance indices and threatened species associations at country-wide scale. Aquat. Conserv. Mar. Freshw. Ecosyst. 26, 57-75. http://dx.doi.org/10.1002/aqc.2605.

van Wilgen, B.W., Forsyth, G.G., Le Maitre, D.C., Wannenburgh, A., Kotzé, J.D.F., van den Berg, E., Henderson, L., 2012. An assessment of the effectiveness of a large, nationalscale invasive alien plant control strategy in South Africa. Biol. Conserv. 148, 28-38. http://dx.doi.org/10.1016/j.biocon.2011.12.035.

van Wyk, A., Smith, G., 2001. Regions of Floristic Endemism in Southern Africa. A Review with Emphasis on Succulents. Umdaus Press, Hatfield. 